\title{
The Study of Association between Helicobacter pylori (H. pylori) and Chronic Obstructive Pulmonary Disease (COPD)
}

\section{Dinesh Deerpaul ${ }^{1 *}$ and Sun Yun Hui ${ }^{2 *}$}

${ }^{1}$ Third year master's student of Jiamusi University, Heilongjiang, China

${ }^{2}$ Department of Respiratory, First affiliated Hospital of Jiamusi University, Heilongjiang, Jiamusi, China

\begin{abstract}
Background: In past years, many studies have been carried out to understand the complex relationship between Helicobacter pylori (H. pylori) infection and Chronic Obstructive Pulmonary Disease (COPD). Few researches have been successful in showing the epidemiologic and serologic evidence for relationship between Helicobacter pylori $(H$. pylori) infection and Chronic Obstructive Pulmonary Disease (COPD).

Objective: In this study, we aimed to investigate the seroprevalence of Helicobacter pylori in patients with COPD and to determine whether there is an association between $H$. pylori infection and COPD.

Method: 40 voluntary patients with COPD and 40 healthy control subjects of similar age and sex were taken as subjects in the study. After the consent form was signed by both the study and control groups, every person was questioned in detail and the relevant data were collected from the case history of the COPD patients. $\mathrm{H}$. pylori-specific IgG was measured with a commercially available Elisa kit from venous blood samples of the study and control groups.

Results: $H$. pylori lgG seropositivity was $57.5 \%$ in the patients with COPD and $37.5 \%$ in the control subject, which suggests that $H$. pylori infection has a higher prevalence in COPD patients than non-COPD patients. Further in our study the mean values of forced expiratory volume in one second (FEV1) and Forced Vital Capacity (FVC) were compared between $H$. pylori seropositive and seronegative COPD patients and non-COPD patients and the $p$ value was not less than 0.05 in any of the comparisons. Finally to see if $H$. pylori infection has any impact in COPD, the patients with COPD were grouped according to their stages of diseases and compared with $H$. pylori lg $G$ seropositivity, the prevalence of $H$. pylori seropositivity did not differ significantly relatively to the stages of COPD i.e. between patients with mild, moderate and severe COPD. Conclusion: The results from our study suggest that there is higher prevalence of $H$. pylori seropositivity in COPD patients than in non-COPD patients, but we were not able to show and prove if $H$. pylori infection is related to COPD since our study was carried out in a very small scale and short period of time. To understand the complex relationship between $H$. pylori infection and COPD, we need much more time and finance, firstly so that we can carry out our study in a larger scale involving much more individuals in our study and control groups and secondly to be able to use more sophisticated and modern technologies to get better and quicker results.
\end{abstract}

Keywords: Chronic Obstructive Pulmonary Disease (COPD); Helicobacter Pylori infection (H. pylori); H. pylori-specific IgG; $H$. pylori IgG seropositivity

\section{Introduction}

Chronic Obstructive Pulmonary Disease (COPD), also known as chronic obstructive lung disease (COLD), and Chronic Obstructive Airway Disease (COAD), among others, is a type of obstructive lung disease characterized by chronically poor airflow. It typically worsens over time, with the main symptoms including shortness of breath, cough, and sputum production [1]. The technology needed to diagnose and quantitative the individual small airway and emphysema phenotypes present in people with COPD is being developed, and should prove helpful in the assessment of therapeutic interventions designed to modify the progress of either phenotype [2]. COPD remains frequent and costly disease representing one of the principal demands of the public health worldwide. Inhaled tobacco smoke and other noxious particles, such as occupational exposures and smoke from biomass fuels, are the most important exogenous factors that influence disease development and progression [3]. The most important bacterial causes of exacerbations of COPD are nontypeable Haemophilus influenzae, Moraxella catarrhalis, Streptococcus pneumoniae and Chlamydia pneumonia [4]. Despite being a treatable and preventable disease, the prevalence continues to rise because of the worldwide epidemic of smoking. It has systemic effects, and common co-morbid conditions such as cardiovascular disease, muscle wasting and osteoporosis may all be linked through a common systemic inflammatory cascade. Spirometry is essential for the diagnosis of
COPD, but the criteria defining airflow limitation are not clear cut for elderly patients and could result in over-diagnosis. However, older patients perceive their symptoms differently, and COPD could also be under-diagnosed in this population [5]. The prevalence of chronic obstructive pulmonary disease (COPD) in China is largely unknown. In a study which was done by Nanshan Zhong and others, Urban and rural population-based cluster samples were randomly selected from seven provinces/cities. All residents 40 years of age or older in the selected clusters were interviewed with a standardized questionnaire revised from the international Burden of Obstructive Lung Diseases (BOLD) study. Spirometry was performed on all eligible participants. Patients with airflow limitation $\left(\mathrm{FEV}_{1} / \mathrm{FVC}<0.70\right)$ were further examined by post-bronchodilator spirometry, chest radiograph, and electrocardiogram. Post-bronchodilator $\mathrm{FEV}_{1} / \mathrm{FVC}$ of less than $70 \%$

${ }^{*}$ Corresponding authors: Sun Yun Hui, First Affiliated Hospital of Jiamusi University, China, Tel: 008615694548069; E-mail: sunyh8@163.com

Dinesh Deerpaul, Jiamusi City, Heilongjiang Province, Chaoyang District, Jiamus University, China, Tel: 008615164518613; E-mail: dineshdeerpaul@yahoo.com

Received December 10, 2013; Accepted January 28, 2014; Published January 30, 2014

Citation: Deerpaul D, Hui SY (2014) The Study of Association between Helicobacter pylori ( $H$. pylori) and Chronic Obstructive Pulmonary Disease (COPD). J Pulm Respir Med 4: 171. doi:10.4172/2161-105X. 1000171

Copyright: (c) 2014 Deerpaul D, et al. This is an open-access article distributed under the terms of the Creative Commons Attribution License, which permits unrestricted use, distribution, and reproduction in any medium, provided the original author and source are credited. 
was defined as the diagnostic criterion of COPD [6]. Chronic obstructive pulmonary disease is a major cause of death and disability in the United States. The most important risk factor for COPD is cigarette smoking. Finally, it will be necessary to conduct more research to identify methods to help the general public adhere to preventive measures and to help COPD patients adhere to prescribed therapies [7]. Smoking is the major risk factor for COPD, accounting for some $90 \%$ of cases. Therefore, smoking cessation remains the most important intervention. Other available pharmacotherapeutic options include corticosteroids, bronchodilators, antibiotics for the treatment of acute exacerbations, mucokinetic agents, and oxygen for the advanced stages of the disease. While it is likely that ongoing research will optimize the use of older agents and identify new treatment options for patients with COPD, smoking cessation will probably remain the most important intervention and should be a key focus of future initiatives aimed at controlling this disease [8]. Chronic Obstructive Pulmonary Disease (COPD) is characterized by an incompletely reversible limitation in airflow. A physiological variable - the forced expiratory volume in one second $\left(\mathrm{FEV}_{1}\right)_{-}$-is often used to grade the severity of COPD. However, patients with COPD have systemic manifestations that are not reflected by the $\mathrm{FEV}_{1}$. Exacerbations occur commonly in patients with moderate or severe chronic obstructive pulmonary disease (COPD) but factors affecting their severity and frequency or effects on quality of life are unknown, suggesting that patient quality of life is not certain to be related to COPD exacerbation frequency [9]. The effects of broadspectrum antibiotic and placebo therapy in patients with chronic obstructive pulmonary disease in exacerbation were compared in a randomized, double-blinded, crossover trial. Exacerbations were defined in terms of increased dyspnea, sputum production, and sputum purulence. Peak flow recovered more rapidly with antibiotic treatment than with placebo. Side effects were uncommon and did not differ between antibiotic and placebo. From the Sections of Respiratory and Infectious Diseases, Department of Internal Medicine, and the Department of Social and Preventive Medicine, University of Manitoba; Winnipeg, Manitoba, Canada [10]. COPD affects more than 5 percent of the population and is associated with high morbidity and mortality [11]. It is the third-ranked cause of death in the United States, killing more than 120,000 individuals each year [4]. As a consequence of its high prevalence and chronicity, COPD causes high resource utilization with frequent clinician office visits, frequent hospitalizations due to acute exacerbations, and the need for chronic therapy (e.g., supplemental oxygen therapy, medication) $[12,13]$. Correct diagnosis of COPD is important because appropriate management can decrease symptoms (especially dyspnea), reduce the frequency and severity of exacerbations, improve health status, improve exercise capacity, and prolong survival [5]. The definition of COPD and its subtypes (emphysema, chronic bronchitis, and chronic obstructive asthma) and the interrelationships between the closely related disorders that cause airflow limitation provide a foundation for understanding the spectrum of patient presentations. COPD-The Global Initiative for Chronic Obstructive Lung Disease (GOLD) - a project initiated by the National Heart, Lung, and Blood Institute (NHLBI) and the World Health Organization (WHO) defines COPD as follows [7]: "Chronic obstructive pulmonary disease (COPD), a common preventable and treatable disease, is characterized by airflow limitation that is usually progressive and associated with an enhanced chronic inflammatory response in the airways and the lung to noxious particles or gases. Exacerbations and co morbidities contribute to the overall severity in individual patients." Chronic bronchitis: Chronic bronchitis is defined as a chronic productive cough for three months in each of two successive years in a patient in whom other causes of chronic cough (e.g., bronchiectasis) have been excluded [8]. Emphysema: Emphysema is defined by abnormal and permanent enlargement of the airspaces distal to the terminal bronchioles that is accompanied by destruction of the airspace walls, without obvious fibrosis (i.e., there is no fibrosis visible to the naked eye) [10]. However, many studies have found increased collagen in the lungs of patients with mild COPD, indicating that fibrosis can be a component of emphysema [9]. While emphysema can exist in individuals who do not have airflow obstruction, it is more common among patients who have moderate or severe airflow obstruction [6,14]. Asthma: "Asthma is a chronic inflammatory disorder of the airways in which many cells and cellular elements play a role. The chronic inflammation is associated with airway responsiveness that leads to recurrent episodes of wheezing, breathlessness, chest tightness, and coughing, particularly at night or in the early morning. These episodes are usually associated with widespread, but variable, airflow obstruction within the lung that is often reversible either spontaneously or with treatment [15]." Interrelationships of COPD subtypes-Early definitions of COPD distinguished different types (i.e., chronic bronchitis, emphysema, asthma), a distinction that is not included in the current definition [16]. Chronic bronchitis and emphysema with airflow obstruction commonly occur together. Persons with chronic bronchitis, emphysema, or both are not considered to have COPD unless they have airflow obstruction [17]. Patients with airflow obstruction due to diseases that have a known etiology or a specific pathology (e.g., cystic fibrosis, bronchiectasis, obliterative bronchiolitis) are not considered to have COPD (subset 10 in the figure). However, these exclusions are loosely defined [18]. Consistent with the idea that significant overlap exists among the different types of COPD, many individuals have bronchial inflammation with features of both asthma and chronic bronchitis/emphysema [19]. The predominant pathologic changes of COPD are found in the airways, but changes are also seen in the lung parenchyma and pulmonary vasculature. In an individual, the pattern of pathologic changes depends on the underlying disease (eg, chronic bronchitis, emphysema, alpha-1 antitrypsin deficiency), possibly individual susceptibility, and disease severity [14]. Airways abnormalities in COPD include chronic inflammation, increased numbers of goblet cells, mucus gland hyperplasia, fibrosis, narrowing and reduction in the number of small airways, and airway collapse due to the loss of tethering caused by alveolar wall destruction in emphysema [13]. Chronic inflammation in chronic bronchitis and emphysema is characterized by the presence of CD8+ T-lymphocytes, neutrophils, and CD68+ monocytes/macrophages in the airways [20]. In comparison, the bronchial inflammation of asthma is characterized by the presence of CD4+ T-lymphocytes, eosinophils, and increased interleukin (IL)-4 and IL-5 [19,21]. The most important risk factor for COPD is cigarette smoking and the amount and duration of smoking contribute to disease severity. Thus, a key step in the evaluation of patients with suspected COPD is to ascertain the number of pack years smoked (packs of cigarettes per day multiplied by the number of years), as the majority ( 80 percent) of patients with COPD have a history of cigarette smoking [22]. It is useful to ask the age of starting and the age of quitting, as patients may underestimate the number of years they smoked. With enough smoking, almost all smokers will develop measurably reduced lung function [5]. While studies have shown an overall "dose-response curve" for smoking and lung function, some individuals develop severe disease with fewer pack years and others have minimal to no symptoms despite many pack years [5]. The exact threshold for the duration/intensity of cigarette smoking that will result in COPD varies from one individual to another. In the absence of a genetic/environmental/occupational predisposition, smoking less than 10 to 15 pack years of cigarettes is unlikely to result in COPD. On the other hand, the single best variable for predicting which adults will have airflow obstruction on spirometry is a history of more than 40 pack 
years of smoking [23]. The chronologically taken environmental/ occupational history may disclose other important risk factors for COPD, such as exposure to fumes or organic or inorganic dusts. These exposures help to explain the 20 percent of patients with COPD (defined by lung function alone) and the 20 percent of patients who die from COPD who never smoked [24]. The three cardinal symptoms of COPD are dyspnea, chronic cough, and sputum production and the most common early symptom is exertional dyspnea. Less common symptoms include wheezing and chest tightness. However, any of these symptoms may develop independently and with variable intensity. These are the three typical ways in which patients with COPD present [11]. Approximately 62 percent of patients with moderate to severe COPD report variability in symptoms (eg, dyspnea, cough, sputum, wheezing, or chest tightness) over the course of the day or week-toweek; morning is typically the worst time of day [25]. Co morbid diseases that may accompany COPD include lung cancer, coronary heart disease, osteoporosis, metabolic syndrome, skeletal muscle weakness, depression, and cognitive dysfunction. Patients may also report a family history of COPD or other chronic respiratory illness $[6,26]$ The findings on physical examination of the chest vary with the severity of the COPD. Early in the disease, the physical examination may be normal, or may show only prolonged expiration or wheezes on forced exhalation. As the severity of the airway obstruction increases, physical examination may reveal hyperinflation (e.g., increased resonance to percussion), decreased breath sounds, wheezes, crackles at the lung bases, and/or distant heart sounds [27]. Other physical examination findings include use of the accessory respiratory muscles of the neck and shoulder girdle, expiration through pursed lips, paradoxical retraction of the lower interspaces during inspiration (i.e., Hoover's sign) [28]. Yellow nicotine stains on the fingers are a clue to ongoing and heavy cigarette smoking. Clubbing of the digits is not typical in COPD (even with associated hypoxemia) and suggests co morbidities such as lung cancer, interstitial lung disease, or bronchiectasis. Evaluation for COPD is appropriate in adults who report dyspnea, chronic cough, chronic sputum production or have had a gradual decline in level of peak activity, particularly if they have a history of exposure to risk factors for the disease (eg, cigarette smoking, indoor biomass smoke) [14]. Especially suggestive subsets include the presence of emphysema in a young individual (eg, age $\leq 45$ years), emphysema in a nonsmoker or minimal smoker, emphysema characterized by predominantly basilar changes on the chest radiograph, or a family history of emphysema [29]. Pulmonary function tests, particularly spirometry, are the cornerstone of the diagnostic evaluation of patients with suspected COPD. In addition, PFTs are used to determine the severity of the airflow limitation, assess the response to medications, and follow disease progression. The most important values measured during spirometry are the forced expiratory volume in one second $\left(\mathrm{FEV}_{1}\right)$ and the Forced Vital Capacity (FVC). The post bronchodilator ratio of $\mathrm{FEV}_{1} / \mathrm{FVC}$ determines whether airflow limitation is present; the post bronchodilator percent predicted value for $\mathrm{FEV}_{1}$ determines the severity of airflow limitation and has been advocated as a dividing point for the diagnosis of COPD $[6,8,30]$. Moreover, in a study of 13,847 subjects in whom an increased mortality was noted among those with an $\mathrm{FEV}_{1} / \mathrm{FVC}<0.70$, but a normal LLN $\mathrm{FEV}_{1} / \mathrm{FVC}$ when compared with those whose $\mathrm{FEV}_{1} / \mathrm{FVC}$ was 0.70 or higher [31]. Forced expiratory volume in 6 seconds-The forced expiratory volume in six seconds $\left(\mathrm{FEV}_{6}\right)$, obtained by stopping the expiratory effort after 6 seconds rather than at cessation of airflow, is an acceptable surrogate for the FVC [32]. FEV1: Forced Expiratory Volume in 1 Second (lung airflow measure). FVC or Forced Vital Capacity: The amount of air which can be forcibly exhaled from the lungs after taking the deepest breath possible. Measuring FVC is done through spirometry testing which helps your doctor determine your lung function. Because COPD causes the air in your lungs to be exhaled at a slower rate and in smaller amounts compared to a normal, healthy person, measuring how well you can forcibly exhale air can help determine the presence of COPD. FEV1/FVC: Forced Expiratory Volume in One Second/Forced Vital Capacity. The normal value for this ratio is above $0.75-85$, though this is age dependent. Values less than 0.70 are suggestive of airflow limitation with an obstructive pattern; restrictive lung diseases often produce a FEV1/FVC ratio which is either normal or high. Measured by a pulmonary function test known as spirometry, FEV1/FVC (FEV1\% or $\% \mathrm{FEV} 1$ ) is a number that represents the ratio of your forced expiratory volume in one second (FEV1) to your forced vital capacity (FVC). The value measures the percentage of the total FVC that is expelled from your lungs during the first second of a forced exhalation. FEV1/FVC is extremely important in the diagnosis of obstructive and restrictive lung diseases [33].

Peak expiratory flow is often used as a measure of airflow limitation in asthma, but may underestimate the degree of airflow limitation in COPD [6]. Pulse oximetry, which is obtained in the majority of patients, has reduced the number of patients who require arterial blood gases (ABGs). However, pulse oximetry does not provide information about alveolar ventilation or hypercapnia $\left(\mathrm{PaCO}_{2}>45 \mathrm{mmHg}\right)$, and assessment of oxygenation by pulse oximetry may be inaccurate in the setting of an acute exacerbation of COPD [34]. When advanced COPD leads to pulmonary hypertension and cor pulmonale, prominent hilar vascular shadows and encroachment of the heart shadow on the retrosternal space may be seen [35]. Computed Tomography (CT) has greater sensitivity and specificity than standard chest radiography for the detection of emphysema, but not chronic bronchitis or asthma. This is particularly true with high resolution CT (i.e., collimation of 1 to $2 \mathrm{~mm}$ ) [36]. However, CT scanning is not needed for the routine diagnosis of COPD. Usually, it is performed when a change in symptoms suggests a complication of COPD (eg, pneumonia, pneumothorax, giant bullae), an alternate diagnosis (eg, thromboembolic disease), or when a patient is being considered for lung volume reduction surgery. Newer CT scanners with higher resolution and new analytical methods can resolve airway dimensions, although the clinical significance of these measures is undefined [37]. The diagnosis of COPD is based upon the following findings [38]. The presence of symptoms compatible with COPD (eg, dyspnea at rest or on exertion, cough with or without sputum production, progressive limitation of activity) are suggestive of the diagnosis. Spirometry showing airflow limitation (i.e., a FEV 1 FVC ratio less than 0.70 or less than the lower limit of normal [LLN] PLUS an $\mathrm{FEV}_{1}$ less than 80 percent of predicted) that is incompletely reversible with inhaled is the hallmark of the diagnosis of COPD. Absence of an alternative explanation for the symptoms and airflow limitation [6] Routine screening spirometry is generally not indicated for adults who have none of the features suggestive of COPD (eg, no dyspnea, cough, sputum production or progressive decline in activity), as asymptomatic mild airflow obstruction does not require treatment [39].

Asymptomatic and nonsmoking subjects with mild airflow obstruction, but no history of asthma, do not have the same progressive decline in lung function that is observed among individuals who have a similar degree of airflow obstruction and are symptomatic or continue to smoke [40]. On the other hand, waiting for patients to report symptoms may miss a large number of patients who have COPD, as 20 percent of individuals with severe airway obstruction due to smoking or asthma will not report symptoms. Decrements in $\mathrm{FEV}_{1}$, even within the normal range, are associated with increased risk of acute cardiac events independent of age, gender, and smoking history [27]. Other aspects of disease, such as the severity of symptoms, risk of exacerbations, and the 
presence of co morbidities, are important to the patient's experience of the disease and prognosis and are included in newer staging systems, such as the revised GOLD classification [7]. Several tools for evaluating symptom severity have been proposed. The GOLD guidelines suggest using instruments such as the modified Medical Research Council (mMRC) dyspnea scale, the Clinical COPD Questionnaire, or the COPD Assessment Tool (CAT) [41]. In our practice, we typically use the mMRC scale. The most widely used tool, the St. George's Respiratory Questionnaire (SGRQ), is a 76 item questionnaire that includes three component scores (i.e., symptoms, activity, and impact on daily life) and a total score. While valuable for research purposes in patients with COPD, asthma, and bronchiectasis, it is too long and complicated for use in routine clinical practice [42]. The Gold guidelines suggest using a combination of an individual's symptoms, history of exacerbations, and $\mathrm{FEV}_{1}$ to assess the exacerbation risk and guide therapy [7]. Symptom severity is assessed using the modified Medical Research Council (mMRC) or COPD assessment test (CAT) [7]. The number of exacerbations in the previous 12 months can be used to predict future risk. A history of zero or one exacerbation in the past 12 months suggests a low future risk of exacerbations, while two or more exacerbations suggest a high future risk [7]. The severity of lung function impairment is stratified based on the post bronchodilator $\mathrm{FEV}_{1}$, using the GOLD classification. These three components are combined as follows:

- Low risk, less symptoms: Typically GOLD 1 or GOLD 2 (mild or moderate airflow limitation) and/or 0 to 1 exacerbation per year and mMRC grade 0 to 1 or CAT score $<10$.

- Low risk, more symptoms: Typically GOLD 1 or GOLD 2 (mild or moderate airflow limitation) and/or 0 to 1 exacerbation per year and $\mathrm{mMRC}$ grade $>2$ or CAT score $\geq 10$.

- High risk, less symptoms: Typically GOLD 3 or GOLD 4 (severe or very severe airflow limitation) and/or $\geq 2$ exacerbations per year and $\mathrm{mMRC}$ grade 0 to 1 or CAT score $<10$.

- High risk, more symptoms: Typically GOLD 3 or GOLD 4 (severe or very severe airflow limitation) and/or $\geq 2$ exacerbations per year and $\mathrm{mMRC}$ grade $>2$ or CAT score $\geq 10$.

Other systems for assessing disease severity in the COPD patient have been proposed. The BODE index, which is calculated based on weight $(\mathrm{BMI})$, airway obstruction $\left(\mathrm{FEV}_{1}\right)$, dyspnea (mMRC dyspnea score), and exercise capacity (six-minute walk distance), has been used to assess an individual's risk of death. This index provides better prognostic information than the $\mathrm{FEV}_{1}$ alone and can be used to assess therapeutic response to medications, pulmonary rehabilitation therapy, and other interventions [43]. Other staging systems for COPD (eg, DOSE, ADO) have also been developed, but are not used routinely in clinical practice. The DOSE staging system comprises dyspnea, airflow obstruction, smoking status, and exacerbation frequency [44], while the ADO staging system combines age, dyspnea (by MRC scale), and airflow obstruction [45]. The $\mathrm{FEV}_{1} / \mathrm{FVC}$ ratio is not used for staging because measurement of FVC becomes less reliable as the disease progresses (the long exhalations are difficult for the patients), thus making the ratio less accurate. Different clinical practice guidelines use different cut-off values, but most are similar to the GOLD staging system [6]. The treatment of patients with stable COPD depends on its stage and type. If type 1 i.e. $(\mathrm{Pa} 02<8.0 \mathrm{kPa})(\mathrm{PaCO} 2<6.6 \mathrm{kPA})$, in its acute state, treat the underlying disorder with high-concentration $\mathrm{O} 2$ and mechanical ventilation if necessary, in its chronic state treat underlying disorder with controlled long term $\mathrm{O} 2$. In the case of type $2 \mathrm{COPD}$ i.e. $(\mathrm{PaO} 2<8.0$ $\mathrm{kPa})(\mathrm{PaCO} 2>6.6 \mathrm{kPa})$, in the acute state treat the underlying disorder with controlled low-concentration $\mathrm{O} 2$ and mechanical ventilation (or tracheotomy) if necessary, in its chronic state treat underlying disorder with controlled long-term $\mathrm{O} 2$ and mechanical ventilation support if necessary. In the treatment of COPD it is also very important that the patient who smokes should stop smoking completely and permanently. Participation in an active smoking cessation programme, together with the use of nicotine replacement therapy, leads to a higher quit rate. In well-motivated patients bupropiion (150 mg once daily increasing to $150 \mathrm{mg}$ 12-hourly on day 7) commenced 1-2 weeks prior to stopping smoking is also a valuable adjunct to smoking cessation. Bupropion is contraindicated in those patients with a history of epilepsy or known CNS tumor and should only be used for 7-9 weeks. Dusty and smokeladen atmospheres should be avoided; this may involve a change of occupation. Respiratory infection should be treated promptly because it aggravates breathlessness and may precipitate type 2 respiratory failures in patients with severe airflow obstruction. Purulent sputum is treated with amoxicillin 250mg 8-hourly (clarithromycin 250-500 mg 12 -hourly if penicillin sensitive) pending sputum culture results. Coamoxiclav $375 \mathrm{mg}$ 8-hourly should be used if there is no response or if a beta-lactamase-producing organism is cultured. The usual causative organisms are Streptococcus pneumoniae or Haephilus influenzae. A 5-10-day course of treatment is usually effective. Well-informed, reliable patients can be given a supply of one of these drugs and start a course of treatment on their own initiative when the need arises. Continuous antibiotic treatment is not advised as it is apt to promote the emergence of drug-resistant organisms within the respiratory tract. Influenza immunization should be offered to all patients each year. Bronchodilator therapy with regular inhaled ant cholinergic agents and short-acting beta2-agonists taken as required provides useful symptomatic relief in the majority of patients. In moderate and severe COPD these agents should be used regularly and in combination, and low-dose inhaled steroids considered in patients with severe COPD and frequent exacerbations requiring hospital admission. These latter agents should not be used routinely. Theophyllines and long-acting beta2-adrenoceptor agonists are of limited value in COPD but may produce small increases in exercise tolerance and quality of life. There is no role for other anti-inflammatory drugs. It is vital to check inhaler use as many patients with COPD struggle to use metered-dose inhalers (MDIs) effectively; dry powder inhalers or large-volume spacer devices are often preferable. The use of home nebulizers to deliver high doses of bronchodilators drugs is controversial. Treatment is expensive and may have important side-effects; however, a few patients may show significant objective or subjective improvements with such treatment.

$H$. pylori infection, a lifelong and often asymptomatic infection of the stomach, profoundly alters gastric immune response that may lead to systemic effects. $H$. pylori persistence leads to chronic inflammation and immune stimulation, which could contribute to several extra gastro-duodenal pathologies. There are a lot of studies regarding the role of $H$. pylori infection in a variety of inflammatory, malign and infectious diseases of the respiratory system [46]. The role of $H$. pylori in the pathogenesis of extra gastric diseases remains controversial. Gastric organisms were first observed more than 100 years ago and their association with gastritis has been recognized since the 1970s [47]. The true implication of these microbes was not fully realized, however, until 1982 when Marshall and Warren identified and subsequently cultured the gastric bacterium, Campylobacter pyloridis, later reclassified as Helicobacter pylori (H. pylori) [48]. H. pylori is a spiral shaped, microaerophilic, gram negative bacterium measuring approximately 3.5 microns in length and 0.5 microns in width. In vitro, it is a slow growing organism that can be cultured on blood agar or selective media such as Skirrow's media incubated at $37^{\circ} \mathrm{C}$ in a 5 percent 
oxygen atmosphere for three to seven days [49]. Small, uniformly sized, translucent bacterial colonies form and the organisms can be morphologically characterized by Gram stain and their typical spiral or rod shaped appearance. High power microscopy reveals that the organism has two to seven unipolar sheathed flagella which enhance its mobility through viscous solutions. If the growth environment is less than ideal, coccoid forms of $H$. pylori can occasionally be seen in culture [49]. There are a number of clinical circumstances in which testing for $H$. pylori is considered. Recommendations for diagnostic testing for $H$. pylori were first proposed by the National Institutes of Health (NIH) in 1994 [50]. More recent guidelines were published in 2006 by the European Helicobacter Study Group (EHSG) [1] and in 2007 by the American College of Gastroenterology (ACG). However, over 80 percent of individuals infected with the bacterium are asymptomatic and it has been postulated that it may play an important role in the natural stomach ecology [51]. Bacterial virulence factors such as the cytotoxin-associated gene pathogenicity island-encoded protein CagA and the vacuolating cytotoxin VacA aid in this colonization of the gastric mucosa and subsequently seems to modulate the host's immune system $[52,13]$. However all patients with proven acute or chronic duodenal ulcer disease and those with gastric ulcers who are $H$. pylori positive should be offered eradication therapy as primary therapy. Treatment is based upon a proton pump inhibitor taken simultaneously with two antibiotics (from amoxicillin, clarithromycin and metronidazole) for 7 days. Compliance, side-effects and metronidazole resistance influence the success of therapy. Second line therapy should be offered to those patients who remain infected after initial therapy once the reasons for failure of first-line therapy (e.g. compliance) have been established. For those who are still colonized after two treatments, the choice lies between a third attempt with quadruple therapy (bismuth, proton pump inhibitor and two antibiotics) or long-term maintenance therapy with acid suppression. Recommendations on the treatment of $H$. pylori taking into account the necessity of the assessment of bacteria sensitivity to antibiotics were outlined. It is particularly important in the regions with high resistance of $H$. pylori to clarythromycin, which in children can exceed 20\% [53]. An increased seroprevalence of $H$. pylori has also been reported in various extra gastrointestinal disorders including skin, vascular, and autoimmune disorders, as well as in some respiratory diseases such as bronchial asthma, bronchiectasis, chronic bronchitis, and lung cancer [50]. However, studies regarding the role of $H$. pylori in the pathogenesis of chronic obstructive pulmonary disease (COPD), i.e. progressive, permanent inflammation of the respiratory system, which has been accepted as a systemic disease, and those correlating $H$. pylori with respiratory functions are scarce. Moreover, a high prevalence of COPD has been found in patients with peptic ulcer [54]. In our study, we investigated the relation of COPD to $H$. pylori seroprevalence and whether this relation correlates with the severity of the disease, measured by respiratory function tests.

\section{Material and Methods}

Before embarking upon the study, our proposal was submitted to the governing body of the hospital hand which is the first affiliated hospital of Jiamusi university where the ethical clearance was taken on $10^{\text {th }}$ of October 2012. After which we started to collect data and look for our subjects. The process of finding our subject which was to look for 40 COPD patients and 40 non-COPD individuals, both male and female between the age of 40 and 80 years, who were never known to have been infected with $H$. pylori. The 40 non-COPD individuals who were selected have never been diagnosed as neither COPD patients nor any other diseases connected to the lungs, that process was completed in nearly more than 2 months. The 40 COPD patients were our study group and the 40 non-COPD individuals were our control group. The interest of our subjects was fully respected and a written consent was taken after fully explaining all the relevant details, its importance and implications. Those who didn't give consent for any reason were excluded from the study. Confidentiality was maintained to the utmost. No names, photographs, documents or results were disclosed or circulated anywhere other than hospital doctors or research guides. The names of the patient did not appear in the final report. The patients who were willing to cooperate with us and who were interested and had no objections to be part of our study were very helpful and cooperative. The COPD patients were from the respiratory departments of the first affiliated hospital of Jiamusi and the central hospital of Jiamusi City. Exclusion criteria for COPD patients were exacerbation of COPD in the last month. The data were collected from the 2 groups of individuals: 40 non-COPD individuals and 40 patients with COPD. Some of the 40 non-COPD patients selected from the hospital but not from the respiratory department, they were mostly from departments like cardiology, surgery endocrinology but mostly were chosen randomly from the city of Jiamusi in the Heilongjiang province of China. The control group consisting of 40 persons shown to have normal pulmonary function and they were not infected with $H$. pylori in the past. Chest radiography was carried out to exclude other respiratory diseases for both non-COPD and COPD patients. The data collected from the 40 non-COPD and 40 COPD individuals were; name, age, gender, address, occupation, hospital number, chief complaint, present illness, history of present illness, medical history, personal history/allergy history (Smoking/Alcohol/Areca Nut/Tobacco/Others), Lymph nodes examination, Surgical procedure undertaken:, Intra-operative problems encountered if any. Apart from these data which were for both the nonCOPD and COPD patients, we noted the values of FEV1, FVC and FEV $1 / \mathrm{FVC}$ ratio from the history case of the COPD patients, these data were very important as they were used afterwards in our study to prove whether $\mathrm{H}$. pylori is related to the severity of COPD. In the respiratory department, COPD was diagnosed on the basis of patient history, physical examination and spirometric data, i.e. forced expiratory volume in $1 \mathrm{~s}$ (FEV 1 ) and forced vital capacity (FVC; expressed as percent of predicted for both). All the patients with COPD included into the study had airway obstruction with an (FEV 1) $<80 \%$ of predicted, an FEV 1/FVC ratio of $<70 \%$, and with no spirometric response to bronchodilators (i.e. an FEV 1 increase 12\% of baseline values) and history of chronic progressive symptoms such as dyspnea and coughing. The control group and the patients with COPD were clinically stable. Patients with malignancy, and systemic, vascular, gastrointestinal and cardiac diseases were also excluded from the study. After our non-COPD and COPD individuals were selected, data and history taking were completed and consent forms were signed, we started our experimental part of our study in January 2013. The experimental part of our study was to look for the amount of infected individuals by $H$. pylori infection among the 40 COPD and 40 nonCOPD subjects. This part of research to find the tendency of $H$. pylori among our subjects was a crucial part of our study since without this result we could not have come to a conclusion of our study. That's why this part of our study was carried out very delicately and it took nearly a year to be completed. The cause of this long duration of the experiment was because firstly: during this experimental part of our study, we had to take the subjects' blood sample and analyze in the laboratory, and the subjects were not always available or free for donating their blood samples, the non-COPD individuals had to attend the hospital to give their blood sample which was very difficult for them since they already had a very hectic time table in their daily life. All the COPD patients were not admitted at the hospital at the same time, some of them were met at the Respiratory Diseases OPD, others had review in the ward of Respiratory Diseases after a period of 3 months after they were 
discharged from the hospital, and these factors delayed the process of collecting blood from the subjects. Secondly what delayed this process was that every time we collected blood from individuals we had to run to the laboratory to analyze it and to look for the result, but the results were not always satisfactory, so we had to repeat the test again by collecting blood from the subjects again. But our subjects were very cooperative and never complained, and in the month of December 2013 we completed our experimental part of our study. The experimental part was to look for the amount of infected individuals by $H$. pylori infections among the 40 COPD and 40 non-COPD subjects. In one week we hardly collected 3 or 4 samples of blood and every time blood samples were collected they were immediately analyzed in the laboratory and the results were noted and evaluated. Some of the COPD patients were easily available since they were found in the wards as in-patients and few were seen as out-patients in the OPD. The experimental part of our study was carried out as follows; ten milliliters of venous blood were drawn from each person and collected into commercially available treated tubes (Yellow-Top Tube (ACD): This tube contains ACD, which is used for the collection of whole blood for special tests. After collection of the whole blood, the blood was allowed to clot by leaving it undisturbed at room temperature. This usually takes 15-30 minutes. Then the clot was removed by centrifuging at 1,000-2,000 $\mathrm{x} g$ for 10 minutes in a refrigerated centrifuge. In laboratories centrifuges are often used to separate suspensions in liquids. Because of their high rotation rates, centrifuges are delicate and can break easily. However, there were only a few simple rules to remember when we used them. We made a counterbalance for the centrifuge tube we wanted to put in the centrifuge. The masses, not volumes, of the tubes should be as close as possible. Unbalanced tubes may permanently damage the centrifuge. We put the tubes opposite each other in the centrifuge. Whenever we had more than two tubes, only the ones opposite each other have to be equal in mass. Then we entered our settings such as rotations per minute. Afterwards we removed the tubes carefully after the centrifuge had completely stopped spinning. This is so that the different suspensions do not mix again. Precautions taken were as follows: We kept the lid closed while the centrifuge was spinning. When balancing our tubes, it was helpful to put a small beaker or a similar object on the balance to hold the tubes upright so we didn't have to take them off the balance to add water or other solvents. Operate a centrifuge on flat, secure surfaces. Unbalanced centrifuges may slowly move across the surface if it's on. We should immediately shut down unbalanced centrifuges to prevent damage to the machine, ourselves, and those around us. We made sure that we always wear gloves. The resulting supernatant is designated serum. Following centrifugation, it is important to immediately transfer the liquid component (serum) into a clean polypropylene tube using a Pasteur pipette. The samples were maintained at $2-8^{\circ} \mathrm{C}$ while handling. If the serum is not analyzed immediately, the serum should be apportioned into $0.5 \mathrm{ml}$ aliquots, stored, and transported at $-20^{\circ} \mathrm{C}$ or lower. But we made sure that the serum was analyzed as soon as it was collected. It is important to avoid freeze-thaw cycles because this is detrimental to many serum components. Samples which are hemolyzed, icteric or lipemic can invalidate certain tests. After getting each and every serum samples, they were immediately used to look for $H$. pylorispecific IgG with a commercially available kit ELISA (Common name Helicobacter pylori urease antibody detection kit, colloidal gold method); English name Hp Urease Immunogold Testing Kit, phonetic You Men Luo Gan Jun Niao Su Mei Kang Ti Jian Ce Shi Ji He (Jiao Ti Jin $\mathrm{Fa}$ ). Data in the form of positive or negative $H$. pylori were collected for both the control and study group.

The genetically engineered strains of Helicobacter pylori urease antigen coated nitrocellulose membrane, colloidal gold labeled
Helicobacter pylori urease antigen gene engineering and other reagents, membrane-based immunochromatography principle, the application of double antigen sandwich into the legal system. For human serum or plasma antibodies against Helicobacter pylori urease qualitative detection. Composition of the test board, disposable dropper, desiccant, instruction manual. Sample Requirements serum with: Whole blood from the vein, the whole blood sample containing no anticoagulant added to the sample collection tube, the blood from the serum was separated after coagulation backup.

Test methods; test serum or plasma samples prior to return to room temperature; from foil pouch test board on a clean level of the stage; samples in the test plate wells plus four drops of blood or plasma clearance (approximately $100 \mathrm{ul}$ ); 10-20 minutes observations over 20 minutes results invalid.

Results; Positive: control line $(\mathrm{C})$ and test line $(\mathrm{T})$ are both red. Negative: the control line is the red line; the test line does not appear Invalid: Control line does not appear which means that the sample volume is not enough, the steps are incorrect or kit failure. Precautions; soldier Swiss biotechnology remind Note: Only for in vitro diagnostic use; must sign in boxes marked validity period; please open the foil bag kit within 1 hour after use, otherwise it will affect the test results.

\section{Results}

Data are expressed as mean value with standard deviation. H. pylori: Helicobacter pylori; COPD: Chronic Obstructive Pulmonary Disease; FVC: Forced Vital Capacity; FEV1: Forced Expiratory Volume in one second; \% prep: \% of predicted values compared by Independentsamples T-test in IBM SPSS.

Table 1 shows the frequencies of the Age, gender smoking and alcohol habits of the COPD and non-COPD individuals. In all individuals, the serum $H$. pylori IgG seropositivity was not correlated with age, gender and smoking and alcohol habits (for both groups $\mathrm{p}>0.05$ ), i.e. age, gender and smoking/alcohol for both the study and control groups didn't have any impact in the relationship between $H$. pylori and COPD. Both the COPD and non-COPD groups were approximately equally distributed with nearly the same range of ages, gender, smoking/alcohol habits so as to avoid distraction of our aim of study, since the aim of our study was to find the relation between $H$. pylori infection and COPD patients among a randomly chosen population.

Figure 1 shows the percentage of $H$. pylori seropositive population for both the groups COPD and non-COPD. The prevalence of H. pylori seropositive subjects was significantly higher in the group of COPD patients (57.5\%) than non-COPD individuals (37.5\%).

Table 2 shows the percentage of $H$. pylori seropositive individuals

\begin{tabular}{|c|c|c|}
\hline Parameters & COPD & Non-COPD \\
\hline Age & $66 \pm 2.77$ & $65 \pm 3.39$ \\
\hline GENDER male/female & $65 \% / 35 \%$ & $52.5 \% / 47.5 \%$ \\
\hline Smoking/Non-Smoking & $67.5 \% / 32.5 \%$ & $75 \% / 25 \%$ \\
\hline Alcohol/Non-alcoholic & $74 \% / 26 \%$ & $83 \% / 17 \%$ \\
\hline
\end{tabular}

Table 1: Numerical data are expressed as mean value with standard deviation frequencies as number and percentage of study subjects with certain variable.

\begin{tabular}{|c|c|}
\hline Characteristics & COPD patients $(\mathrm{n}=40)$ \\
\hline Mild COPD & $35 \% \pm 2.1$ \\
\hline Moderate COPD & $62.5 \% \pm 4.6$ \\
\hline Severe COPD & $2.5 \% \pm 0.03$ \\
\hline
\end{tabular}

Table 2: Frequency of the $H$. pylori infection in COPD patients. 
among the COPD patients when divided into 3 groups; Mild COPD, Moderate COPD and Severe COPD. Mild COPD had a 35\% of H. pylori seropositive individuals, whereas Moderate and Severe had 62.5\% and $2.5 \%$ respectively.

Table 3 shows the mean baseline values of spirometric parameters of $H$. pylori seropositive and seronegative COPD patients. The three spirometric paramers which are FEV1, FVC and FEV1/FVC were compared with the $H$. pylori seropositive and seronegative COPD patients. The mean values of FEV1, FVC and FEV1/FVC for the seropositive COPD patients were as follows $(54.2 \pm 11.2,54.1 \pm 6.4,1.00$ \pm 0.02 respectively with $\mathrm{p}>0.05$ ), whereas for seronegative subjects it showed $(54.3 \pm 10.5,52.4 \pm 11.1,1.04 \pm 0.04$ respectively with $\mathrm{p}>0.05)$. There was a negative relationship between the 3 spirometric values (FEV 1, FVC, and FEV1/FVC) and H. pylori IgG seropositivity in all patients with COPD i.e. $\mathrm{p}>0.05$.

Table 4 shows mean baseline values of spirometric parameters in H. pylori seropositive and seronegative non-COPD study subjects. The results are as follows; FEV1, FVC and FEV1/FVC were $95.0 \pm 8.2,84$ $\pm 3.4,1.13 \pm 0.03$ respectively for seropositive non-COPD subjects, whereas FEV1, FVC and FEV1/FVC were $93.0 \pm 9.5,83.0 \pm 6.1$ and $1.12 \pm 0.2$ respectively for non-COPD subjects with $\mathrm{p}>0.05$.

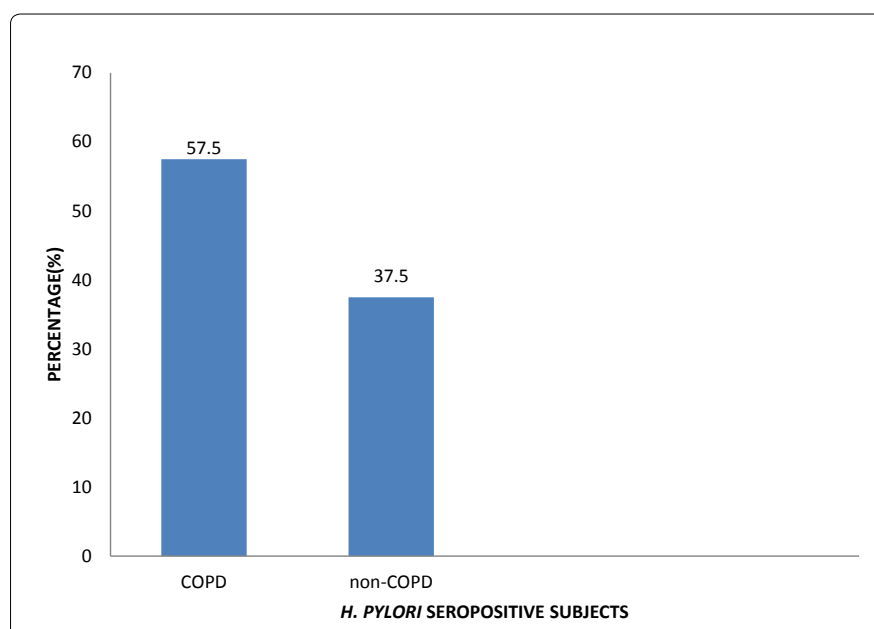

Figure 1: Prevalence of $H$. pylori seropositivity in the examined groups.
Table 5 shows mean baseline values of spirometric parameters in both COPD and non-COPD study subjects together. The results were as follows: FEV1, FVC, FEV1/FVC: $55.0 \pm 6.2,52.9 \pm 2.1$ and $1.04 \pm 0.01$ respectively for all COPD patients. And FEV1, FVC, FEV1/FVC were $93.8 \pm 8.4,83.5 \pm 5.1$ and $1.12 \pm 0.04$ respectively for all non-COPD individuals. The value of $\mathrm{p}$ was greater than 0.05 for both groups when they were analyzed to find the significance level.

\section{Discussion}

In past years many studies have been conducted to understand the complex relationship between $H$. pylori and COPD, some researchers had been successful in their studies and were able to find how $H$. pylori infection is related to COPD but few were not able to do so, that's why they looked forward to investigate more and study deeply the relationship between $H$. pylori and COPD. Our study was about the complex relationship between $H$. pylori and COPD as well, the aim of the study was to find the seroprevalance of $H$. pylori infection among COPD patients and to see whether $H$. pylori has any impact or correlates with COPD. That's why in our study we included 40 COPD patients and 40 non-COPD individuals so as to compare the seroprevalance of $H$. pylori between these to 2 groups. After studying our 40 COPD and 40 non-COPD subjects, we saw a higher prevalence of $H$. pylori among the 40 COPD patients than the 40 non-COPD controls. Figure 1 above shows the percentage of $H$. pylori seropositive population for both the groups: COPD and non-COPD. The prevalence of $H$. pylori seropositive subjects in the group of COPD patients was $57.5 \%$. The group of COPD subjects consisted of both men and women between the age of 40 and 80. The criteria for choosing them were exacerbation of COPD in the last few months or in the same year in which they were being studied. We also made sure that the COPD patients were not suffering from any others diseases related to the pulmonary system and that they never followed any treatment related to $H$. pylori infection. The percentage of H. pylori seropositive non-COPD individuals was $37.5 \%$. These 40 nonCOPD individuals were chosen randomly from the city of Jiamusi, Heilongjiang, China and from the first affiliated hospital of Jiamusi and the city hospital of Jiamusi. The age and the gender of the 40 non-COPD individuals were approximately matched with those of the COPD patients, i.e. there were both men and women between the age of 40 and 80 years. The non-COPD individuals had never been diagnosed as COPD patients in their life and they had never followed any treatments

\begin{tabular}{|c|c|c|c|}
\hline Spirometric parameter & $\begin{array}{c}\text { H. pylori seropositive COPD } \\
\text { patients }(\mathrm{n}=23)\end{array}$ & $\begin{array}{l}\text { H. pylori seronegative } \\
\text { COPD patients }(\mathrm{n}=17)\end{array}$ \\
\hline FEV1 (\%pred) & $54.2 \pm 11.2$ & $54.3 \pm 10.5$ \\
\hline FVC (\%pred) & $54.1 \pm 6.4$ & $52.4 \pm 11.1$ \\
\hline FEV1/FVC & $1.00 \pm 0.02$ & $1.04 \pm 0.04$ \\
\hline
\end{tabular}

Table 3: Mean baseline values of spirometric parameters in $H$. pylori seropositive and seronegative COPD patients.

\begin{tabular}{|c|c|c|c|}
\hline Spirometric parameter & $\begin{array}{l}\text { H. pylori seropositive non-COPD } \\
\text { patients }(n=15)\end{array}$ & $\begin{array}{l}\text { H. pylori seronegative non-COPD } \\
\text { patients }(n=25)\end{array}$ & P-value \\
\hline FEV1 (\%pred) & $95.0 \pm 8.2$ & $93.0 \pm 9.5$ & $>0.05$ \\
\hline FVC (\%pred) & $84.0 \pm 3.4$ & $83.0 \pm 6.1$ & $>0.05$ \\
\hline FEV1/FVC & $1.13 \pm 0.03$ & $1.12 \pm 0.02$ & $>0.05$ \\
\hline
\end{tabular}

Table 4: Mean baseline values of spirometric parameters in $H$. pylori seropositive and seronegative non-COPD study subjects.

\begin{tabular}{|c|c|c|}
\hline Spirometric parameter & $\begin{array}{c}\text { Study(COPD } \\
\text { Patients) }(n=40)\end{array}$ & Control(non-COPD) (n=40) \\
\hline FEV1 (\%pred) & $55 \pm 6.2$ & $93.8 \pm 8.4$ \\
\hline FVC (\%pred) & $52.9 \pm 2.1$ & $83.5 \pm 5.1$ \\
\hline FEV1/FVC & $1.04 \pm 0.01$ & $1.12 \pm 0.04$ \\
\hline
\end{tabular}

Table 5: Mean baseline values of spirometric parameters in COPD and non-COPD study subjects. 
connected to the pulmonary system and in their past history they were also not known to any $H$. pylori infection diseases. The high prevalence of $H$ pylori IgG in the blood of the COPD patients compared to the nonCOPD ones suggested that $H$. pylori infection may had a significance to COPD. It was a challenge for us to take our study to a higher level and find the correlation of the H. pylori and COPD. To begin with we started reading a lot of articles which were similar to ours and found that in 2010 Nahlaf Khattab and his team studied about the seroprevalence of Helicobacter Pylori in patients with Chronic Obstructive Pulmonary Disease. They revealed that patients with COPD have a higher seroprevalence of $H$. pylori infection especially with virulent (CagA) strains. They think the activation of inflammatory mediators by $H$. pylori infection might be the pathogenetic mechanism of the disease [55]. According to Kenneth, Tsang W and his team their study is the first report of a high seroprevalence of $H$. pylori specific to active bronchiectasis irrespective of its etiology. Although the evidence of an association between the seroprevalence of $H$. pylori and bronchiectasis appears strong, they were unable to isolate $H$. pylori in the sputum of bronchiectatic patients. To their knowledge, H. pylori has not been isolated in sputum although it has been identified by using Gram film examination of tracheal aspirate in mechanically ventilated patients in the intensive care setting [56]. Some other researchers have also been successful in finding a higher prevalence of $H$. pylori in COPD patients than in healthy controls [54,57]. In 2011, Seyyed Hamid Hashemi, Ebrahim Nadi, Mehrdad Hajilooi, Mohammad-Ali Seif-Rabiei and Uldoz Rousta found that there is some evidence indicating the role of Helicobacter pylori infection in pathogenesis of extra gastrointestinal diseases including skin, vascular, and autoimmune disorders, as well as some respiratory diseases. The aim of their study was to investigate the association between $H$. pylori and chronic obstructive pulmonary disease (COPD). In a case-control study, 90 patients with COPD and 90 age and sex matched control subjects were included. Serum samples were tested for anti-H. pylori and anti-CagA IgG by ELISA. A physician completed a questionnaire including demographic characteristics, habitual history, and spirometric findings for each patient. Of 90 patients with COPD 66 (51\%) had mild, 31 (34.4\%) moderate, and 13 (14.4\%) sever disease. There was no significant association between $H$. pylori IgG seropositivity and COPD and serum levels of anti-CagA IgG were significantly higher in patients with COPD than in the control subjects $(\mathrm{P}<0.05)$. The results suggest that there is an association between CagA-positive $H$. pylori infections and COPD. Further studies should be planned to investigate the potential pathogenic mechanisms that might underlie these associations [58]. Our statistics showed that the percentage of $H$. pylori seropositive individuals among the COPD patients when divided into 3 groups; Mild COPD, Moderate COPD and Severe COPD, Mild COPD had a $35 \%$ of $H$. pylori seropositive individuals, whereas Moderate and Severe had $62.5 \%$ and $2.5 \%$ respectively shown in Table 2 above. No association was observed between $H$. pylori infection and severity of COPD. Despite we didn't find any connection between the 3 stages of COPD and H. pylori, it is unfair to draw the conclusion that $H$. pylori doesn't have any association with COPD since our study group was very small. We took only 40 COPD patients in our study which was not enough to get good results and prove whether $H$. pylori had any significance to the different stages of COPD. We were very unfortunate to have limited time and finance to deal with a small population as subjects in our study but hopefully in future we would be able to show that $H$. pylori infection can affect COPD patients in such a way that their disease can be deteriorated, for that we need to study a larger amount of population and get more data in a greater scale. In conclusion, $H$. pylori infection may be associated with COPD. Further studies should be undertaken to clarify the potential underlying pathogenetic mechanisms [3]. Table 3 shows the mean baseline values of spirometric parameters of $H$. pylori seropositive and seronegative COPD patients. The three spirometric paramers which are FEV1, FVC and FEV1/FVC were compared with the H. pylori seropositive and seronegative COPD patients. The mean values of FEV1, FVC and FEV1/FVC for the seropositive COPD patients were as follows $(54.2 \pm 11.2,54.1 \pm 6.4,1.00 \pm 0.02$ respectively with $\mathrm{p}>0.05)$, whereas for seronegative subjects it showed $(54.3 \pm 10.5,52.4 \pm 11.1$, $1.04 \pm 0.04$ respectively with $\mathrm{p}>0.05)$. There was a negative relationship between the 3 spirometric values (FEV 1, FVC, and FEV1/FVC) and $H$. pylori IgG seropositivity in all patients with COPD i.e. $\mathrm{p}>0.05$. Table 4 shows mean baseline values of spirometric parameters in $H$. pylori seropositive and seronegative non-COPD study subjects. The results are as follows; FEV1, FVC and FEV1/FVC were 95.0 \pm 8.2, $84 \pm 3.4,1.13 \pm$ 0.03 respectively for seropositive non-COPD subjects, whereas FEV1, FVC and FEV1/FVC were 93.0 $\pm 9.5,83.0 \pm 6.1$ and $1.12 \pm 0.2$ respectively for non-COPD subjects with $\mathrm{p}>0.05$. Table 5 shows mean baseline values of spirometric parameters in both COPD and nonCOPD study subjects together. The results were as follows: FEV1, FVC, FEV1/FVC: $55.0 \pm 6.2,52.9 \pm 2.1$ and $1.04 \pm 0.01$ respectively for all COPD patients. And FEV1, FVC, FEV1/FVC were $93.8 \pm 8.4,83.5 \pm 5.1$ and $1.12 \pm 0.04$ respectively for all non-COPD individuals. The value of $\mathrm{p}$ was greater than 0.05 for both groups when they were analyzed to find the significance level. To conclude we would like to say that study was not so similar to the previous studies carried out in past years in terms of experiment carried out to find the relationship between $H$. pylori and COPD, as well as in terms of the medium and platform used to carry out the study. Some of the previous researchers measured the antiCagA IgG, others looked for specific H. pylori DNA, and few studied the histological changes of bronchial tissue, and the role of eradication therapy of $H$. pylori in the course of COPD were observed to confirm the role of $H$. pylori infection, as far as our study was concerned, we didn't have such facilities to go so deep in experimenting these mediators, our study was based on a clinical experiment, i.e. we had to work with COPD patients and examined their blood to look for $H$. pylori IgG prevalence and to compare the results with the COPD parameters to see whether $H$. pylori infection had any significance or any correlation with COPD.

\section{Conclusion}

In conclusion, in a cross-sectional study including male and female COPD patients and non-COPD matched controls, we found significantly higher prevalence of $H$. pylori seropositivity in COPD patients with no significant difference between patients with smoking habits, age and gender. The percentage of $H$. pylori seropositive individuals in mild, moderate and severe COPD patients didn't have any significance, which indicated that $H$. pylori infection didn't correlate with the staging of COPD i.e no association was observed between $H$. pylori infection and severity of COPD. While the mean values of the spirometric parameters: FEV1, FVC, FEV1/FVC did not differ significantly when compared with $H$. pylori IgG. Our findings support the need of further larger prospective studies in order to assess the complex relationship between $H$. pylori infection and COPD. In our study it has been shown that COPD patients have the tendency to have higher prevalence of $H$. pylori than non-COPD controls, and in order to assess the complex relationship between $H$. pylori infection and COPD, our study and findings support the need of further larger prospective studies which need more time and a higher budget.

\section{Review of Literature}

Further studies designed to evaluate the effects of $H$. pylori on the respiratory tract and to identify $H$. pylori in the bronchiectatic 
respiratory tracts, and clinical longitudinal studies to evaluate the effects of treatment of $H$. pylori in bronchiectasis should follow this study [59]. Despite the fact that the role of H. pylori in pathogenesis of COPD remains controversial, the activation of inflammatory mediators by $H$. pylori infection and during the course of COPD may explain the potential ethiopathogenetic role of $H$. pylori. It is well known that $\mathrm{CagA}+H$. pylori strains stimulate the release of proinflammatory cytokines including IL (interleukin)-1, IL-8, and tumor necrosis factor- $\alpha$ (11). CagA+ strains also cause severe gastric inflammation in association with increased serum levels of IL-17 and IL-23 13]. In 2011 Seyyed Hamid Hashemi and others also worked on the relation between $H$. pylori and COPD and found that the Serum levels of antiCagA IgG were significantly higher in patients with COPD than in the control subjects $(\mathrm{P}<0.001)$ but no association was observed between $H$. pylori infection and severity of COPD also no significant association between $H$. pylori IgG seropositivity and COPD [13]. In a study conducted by Anastasios Roussos and others in 2004, an increased seroprevalence of Helicobacter pylori (H. pylori) and especially of the high virulent cytotoxin-associated gene-A (CagA) positive strains has been found in several extragastroduodenal pathologies, characterized by activation of inflammatory mediators. Another recent study conducted by Fullerton et al. reported no association between $H$. pylori serologic status and either COPD, asthma, allergic disease or decline in lung function, the latter also observed that individuals with serological evidence of $H$. pylori exposure have a lower lung function as measured by FEV1 and FVC, and that this association disappeared after statistical adjustment for either socio-economic status or height [60]. In a study conducted in patients with bronchiectasis, a higher value of $H$. pylori seroprevalence was detected. Sputum amount within $24 \mathrm{~h}$, which is an important marker of disease activity in bronchiectasis, was shown to correlate with the $H$. pylori immunoglobulin level in the same study. Although these results do not indicate a clear role of $H$. pylori in the pathogenesis of bronchiectasis, they may suggest a pro-inflammatory role for $H$. pylori, which may act in concert with other specific factors [61]. In an H. pylori seroprevalence study on patients with bronchial asthma, neither a significant difference between asthmatic patients and the control group was detected, nor was a correlation found between serum $H$. pylori levels and respiratory functions unlike in 2000, Tsang et al estimated the prevalence of $H$. pylori infection in a cohort of 90 patients with bronchial asthma. Helicobacter pylori seroprevalence did not differ significantly between asthmatic and control subjects (47.3 $\% \mathrm{v} / \mathrm{s} 38.1 \%, \mathrm{P}>0.05$ ), while serum concentration of IgG antibodies against $H$. pylori did not correlate with spirometric values and duration of asthma. The authors concluded that bronchial asthma might not be associated with $H$. pylori infection [62]. On the other hand, in another study, lung functions parameters (forced expiratory flow: 50 and 75\%) were significantly lower in pediatric patients with asthma and $H$. pylori infection compared to patients with asthma without $H$. pylori infection. Although there are numerous studies relating a higher $H$. pylori seroprevalence to chronic bronchitis, studies about the relation of $H$. pylori infection with COPD are too sparse, and a correlation between H. pylori IgG levels and pulmonary function tests has not been shown in patients with COPD so far. Moreover, it has been reported that the risk of chronic bronchitis may be increased in $H$. pylori infected patients. But no statistically significant difference, as regards the spirometric values, was detected between $H$. pylori infected COPD patients and uninfected ones.IIn 2013 Pamela J Jensen, MD, Attending Pathologist from Texas Health Presbyterian, Hospital Dallas talked about Acute and Chronic gastritis due to Helicobacter Pylori. She mentioned that Injury to the gastric mucosa is associated with epithelial cell damage and regeneration. The term gastritis is used to denote inflammation associated with mucosal injury. However, epithelial cell injury and regeneration are not always accompanied by mucosal inflammation. This distinction has caused considerable confusion since gastritis is often used to describe endoscopic or radiologic characteristics of the gastric mucosa rather than specific histologic findings. Epithelial cell damage and regeneration without associated inflammation is referred to as "gastropathy" $[63,64]$.

The causes, natural history, and therapeutic implications of gastropathy differ from gastritis:

- Gastropathy is usually caused by irritants such as drugs (eg, nonsteroidal antiinflammatory agents), alcohol, bile, circulatory failure, and chronic congestion.

- Gastritis is usually due to infectious agents (such as Helicobacter pylori [H. pylori]) and autoimmune and hypersensitivity reactions.

Most classification systems distinguish acute, short-term from chronic, long-term disease. The terms acute and chronic are also used to describe the type of inflammatory cell infiltrate. Acute ("active") inflammation is usually associated with neutrophilic infiltration, while chronic inflammation is usually characterized by mononuclear cells, chiefly lymphocytes, plasma cells and macrophages. A practical clinicopathologic framework for the classification of gastritis and gastropathy based upon these factors can be proposed [63].

Acute and chronic gastritis due to $H$. pylori will be reviewed here [65,66]. Although described separately, most patients with $H$. pylori infection will show features of both acute and chronic gastritis. The other forms of gastritis and gastropathy and other issues related to $H$. pylori are discussed separately. Again in 2013 Sheila E Crowe, MD, FRCPC, FACP, FACG, AGAF, Professor of Medicine, from University of California, San Diego wrote about the association between Helicobacter pylori infection and duodenal ulcer. She said that the majority of patients with duodenal ulcer (DU) are infected with Helicobacter pylori (H. pylori). However, in multicenter trials, $H$. pylori was absent in almost 30 percent of patients with an endoscopically documented duodenal ulcer [67]. Studies that have investigated these patients found that they have generally had a shorter duration of symptoms and that many had regularly used nonsteroidal antiinflammatory drugs (NSAIDs) [68-70]. Such patients have a significantly worse outcome, especially if treated empirically for $H$. pylori infection. Thus, $H$. pylori status should be determined in all ulcer patients before initiating treatment [70]. High acid output may be a cause of recurrent DU in patients in whom $H$. pylori has been eradicated [71]. A variety of other causes are responsible for the remaining cases. The link between $H$. pylori and DU will be reviewed here. The pathophysiology of $H$. pylori infection as it relates to gastrointestinal disease in general is discussed separately.

\section{Evidence Linking Helicobacter Pylori To Duodenal Ulcers}

There are several lines of evidence that implicate H. pylori as a major etiologic factor in duodenal ulcers (DU):

- H. pylori is present in most patients who have a DU that is not related to NSAID use

- H. pylori infection is detectable before the occurrence of DU and appears to be a risk factor for the disorder

\section{- Eradication of H. pylori prevents DU recurrence}

Incidence of $H$. pylori in patients with duodenal ulcer-Early studies noted a high incidence of $H$. pylori infection (then called Campylobacter pylori) in patients with DU [72]: subsequent reviews confirmed that $H$. 
pylori is detectable in 80 to 95 percent of these patients [73]. These data were supported by reports which found that the prevalence of $H$. pylori is negligible in populations in which ulcer disease is rare [74].

In this year 2013 Sheila E Crowe, MD, FRCPC, FACP, FACG, AGAF Professor of Medicine from the University of California, San Diego talked about the treatment regimens for Helicobacter pylori. She said multiple regimens have been evaluated for Helicobacter pylori $(H$. pylori) therapy in randomized controlled trials [3,48,75-77]. Despite the number of studies, the optimal therapeutic regimen has not yet been defined. The treatment regimen that is selected must be effective, but considerations such as cost, side effects, and ease of administration should also be taken into account.

This topic review will discuss treatment regimens for $H$. pylori. The indications and diagnostic tests for $H$. pylori infection, as well as the bacteriology and epidemiology, are discussed elsewhere.

\section{Initial Therapy}

Various drug regimens have been proposed for the initial treatment of $H$. pylori infection [78,1]. These include triple, quadruple, or sequential therapy regimens. Triple therapy should be used in areas where clarithromycin resistance is low ( $<15$ percent). However, when clarithromycin resistance is high ( $\geq 15$ percent), quadruple therapy should be used to treat $H$. pylori $[52,54,60,61,46]$.

Triple therapy-The regimen most commonly recommended for first line treatment of $H$. pylori is triple therapy with a proton pump inhibitor (PPI) (lansoprazole $30 \mathrm{mg}$ twice daily, omeprazole $20 \mathrm{mg}$ twice daily, pantoprazole $40 \mathrm{mg}$ twice daily, rabeprazole $20 \mathrm{mg}$ twice daily, or esomeprazole $40 \mathrm{mg}$ once daily), amoxicillin ( $1 \mathrm{~g}$ twice daily), and clarithromycin (500 mg twice daily) for 7 to 14 days. We suggest treatment for 10 days to two weeks. A longer duration of treatment (14 versus 7 days) may be more effective in curing infection but this remains controversial $[77,79,57]$. A meta-analysis suggested that extension of PPI-based triple therapy from 7 to 14 days was associated with a 5 percent increase in eradication rates [57]. Most studies included were based upon amoxicillin-based triple therapy. In 2012 Yemisen M, Mete B, Kanbay A, Balkan II and Ozara R wrote that Helicobacter pylori (HP) is recognized as a common chronic human bacterial infection and is the most common cause of gastritis. Recent studies suggest an increased HP prevalence in patients with various extra-digestive inflammatory diseases. Since many respiratory diseases are characterized by chronic inflammation as well as increased immune response, and HP may enter the nasopharyngeal cavity by gastroesophageal reflux, an association between respiratory disorders and HP infection has been suggested. Several studies discover HP in clinical samples from the patients with upper respiratory system infections. Even some of them revealed a relief after the treatment directed to HP eradication. However some studies do not support this theory and whether this association means a definite proof of a causal relationship between $\mathrm{HP}$ and respiratory diseases needs to be clarified [80]. In 2012 Wang Y, Bi Y, Zhang L and Wang C published an article in the International Journal Medical Sciences after doing a study to find whether Helicobacter Pylori Infection is associated with Asthma risk. In this study, they evaluated the possible relationship between $H$. pylori infection and asthma risk by performing a quantitative meta-analysis of the published case-control studies. The results failed to suggest a significant association between $H$. pylori infection and asthma risk. Similar results were shown in the subgroup analyses regarding ethnicity, source of controls and CagA status. Previously, a number of studies reported that $H$. pylori infection might play a beneficial role for allergy asthma [81-84]. Nevertheless, most of the studies were crosssectional. Compared with case-control studies, cross-sectional design may underestimate the possible risk. Only a proportion of the studies were case-control; however, the results were far from being conclusive. Therefore, they deliberately screened the case-control studies and conducted a pooled analysis assessing the relationship. The crude ORs were calculated according to the raw data obtained from the literature. We did not perform a meta-analysis of the adjusted ORs because adjustment was not comparable among the studies. Considering the potential effect of the interactions between $H$. pylori infection and genetic variation on the risk [84], they performed subgroup analyses stratified by ethnicity. In the subgroup with respect to Asians, Caucasians and mixed ethnicities, no associations could be observed. The data indicated little influence of genetic variations on the risk. Then, they conducted subgroup analyses stratified by source of controls and CagA status, respectively, taking into account the potential effects of the confounding factors on the results. Similarly, no associations could be observed in these subgroups, implying that these factors might exert little influence on the risk. In their study, the included studies used a stable serological method, ELISA, as a unique approach for detecting the presence of $H$. pylori infection. Nevertheless, the serology of $H$. pylori is not a reliable criteria for detecting its effect on asthma. The serologic tests could not give them any information on current $H$. pylori infection. Therefore, a number of further investigations using multiapproaches such as immunhistochemistry, polymerase chain reaction and smears for exploring the presence of $H$. pylori are required. The study had several limitations. Firstly, the papers identified in their study were limited to those openly published up to Jul 2012; it is possible that some related published or unpublished studies that might meet the inclusion criteria were missed, resulting in any inevitable bias, though the funnel plots and the Egger's tests failed to show any significant publication bias. Secondly, the results may be interpreted with care because of the limited number and small sample sizes of each included studies. Thirdly, subgroup analyses regarding other confounding factors such as smoking status, age and gender have not been conducted in the present study because sufficient information could not be extracted from the primary literature. In summary, the association of $H$. pylori infection and asthma risk were assessed by pooling the included data via a systematic meta-analysis. The results failed to suggest a significant association between $H$. pylori infection and asthma risk. Future welldesigned investigations with large sample sizes are required to get a more confidential conclusion [85]. In 2012 Sarfaraz Ahmed Hasni wrote an article in the journal of Medscape about the role of Helicobacter pylori Infection in Autoimmune Diseases and his conclusion was that $H$. pylori infection is very common and widespread. It has survived in its host (humans) for at least the last 58000 years. H. pylori have extensive interactions with the immune system resulting in its down regulation. Their role as a causative agent of autoimmune diseases in genetically susceptible host has been extensively studied. Studies looking at the role of $H$. pylori in various autoimmune diseases found mixed results with some even suggesting a protective effect. However, mechanistic studies establishing causality are lacking. Further research looking at the possible role of $H$. pylori in autoimmune diseases is needed [86]. In 2012 Minov, Jordan, Karadzinska-Bislimovska, Jovanka, Vasilevska, Kristin, Risteska-Kuc, Snezana, Stoleski, Saso, Mijakoski and Dragan together wrote an article about Helicobacter Pylori Infection in never-smoking male patients with Chronic Obstructive Pulmonary Disease and its relation to lung function. They found out that there is a recent epidemiologic and serologic evidence for relationship between Helicobacter pylori (H. pylori) infection and Chronic Obstructive Pulmonary Disease (COPD). In order to assess the relationship between $H$. pylori infection and COPD and its impact on lung function they performed a cross-sectional study including 84 never-smoking male patients with COPD and an equal number of never-smoking males 
without chronic respiratory disease matched to the COPD patients by age. Evaluation of the study subjects included evaluation of $H$. pylori serological status, baseline and post bronchodilator spirometry. We found significantly higher $H$. pylori seropositivity in COPD patients than in controls (76.2 Vs 34.5\%, p=0.041). The prevalence of $H$. pylori seropositivity did not differ significantly between patients with mild, moderate and severe COPD. Borderline significance was registered for the difference of the forced expiratory volume in one second (FEV1) mean value between seropositive and seronegative COPD patients (56.4 vs. 59.2, $\mathrm{p}=0.063$ ). The mean degree of FEV1 reversibility did not differ significantly between seropositive and seronegative COPD patients. Our findings indicate that in cross-sectional analysis there is higher prevalence of $H$. pylori seropositivity in COPD than in non-COPD patients, as well as that $H$. pylori infection has not significant impact on lung function in COPD patients [87]. In 2011 Malfertheiner MV, Kandulski A, Schreiber J and Malfertheiner P did a systematic review of the literature about Helicobacter pylori infection and the respiratory system and found that recent studies suggest an increased Helicobacter pylori prevalence in patients with various extra digestive inflammatory diseases. Similar to $H$. pylori infection, many respiratory diseases are characterized by chronic inflammation as well as increased immune response. Recent studies have evaluated the relation between various respiratory disorders and $H$. pylori infection. The aim of this systematic review was to scrutinize the relevant literature and the mechanisms that could underlie a role for $H$. pylori infection in respiratory diseases. Relevant literature regarding pathophysiological mechanisms and clinical epidemiology of $H$. pylori and different respiratory diseases has been systematically identified and analyzed by two independent reviewers according to a Pub Med search for English language (until week 14, April 2010). At present, there is no definite proof of a causal relationship between $H$. pylori and respiratory diseases. Both $H$. pylori and various respiratory diseases are characterized by the release of proinflammatory cytokines and attraction of granulocytes as well as Band T-cell-mediated response, though a pathophysiological association has not been proven. Neither the role of genetic predisposition of the host nor the presence of virulence factors nor the impact of $H$. pylori eradication have been studied in detail and definitely need further evaluation [88-90]. In 2011 Ahmed, Azza M, Motawie, Ayat A, ElSahrigy, Sally A. F, Kantoush, Nagwa A, Abdel-Ghany, Somaya M., Abdel-Shakour and Usama studied about Helicobacter Pylori infection in Egyptian children with Bronchial Asthma. The objective of this study was to assess the helicobacter pylori infection in a group of Egyptian children with bronchial asthma to determine whether there is a relationship between $H$. pylori infection and bronchial asthma or not. Patients and methods: This study was conducted on 60 children aged 8-17 years of both sex. They were taken from out patients' pediatrics clinics of Alzahraa University Hospital and National Research Center. The studied cases were classified into two groups: group 1, thirty children with bronchial asthma and group 2, thirty apparently healthy children of matched age and sex as a control group. All studied children were subjected to complete history taking, thorough clinical examination, laboratory investigations (complete blood count, stool analysis, total serum IgE, serum $H$. pylori $\operatorname{IgG}$ antibodies) and pulmonary function tests. Positive cases for $\mathrm{H}$. pylori infection were given treatment specific for eradication of these bacteria (Triple therapy). After wards, they were subjected for follow up using $H$. pylori antigen in the stool, serum $H$. pylori $\operatorname{IgG}$ antibodies pulmonary function tests and Questionnaire to know the frequency of attacks during this period. Results: The mean value of absolute eosinophlic count and IgE were significantly higher in asthmatic group compared to controls. $(\mathrm{p}=0.001)$. Serum $H$. pylori $\operatorname{IgG}$ antibodies were positive in $46.67 \%$ of asthmatic children compared to $33.33 \%$ of controls $(\mathrm{p}=0.92)$. There was no significant difference between seropositive and seronegative $H$. pylori IgG asthmatics regarding gastrointestinal symptoms and pulmonary function tests $(p>0.05)$. There was a significant decrease in the mean value of $H$. pylori IgG antibodies in asthmatic children after eradication therapy $(\mathrm{p}=0.02)$ while there was no significant correlation between serum $H$. pylori $\operatorname{IgG}$ antibodies and any of the pulmonary function tests in asthmatics before and after eradication therapy. Also no difference was found in the frequency of attacks among asthmatic children following eradication therapy. Conclusion: Helicobacter pylori seropositivity does not differ between asthmatic children and controls. Presence or absence of $H$. pylori infection does not affect pulmonary function tests in asthmatic children either before or after the eradication therapy. Helicobacter pylori eradication does not affect the frequency of asthma attacks [91]. In 2008 Kurtran H Uyar ME, Kasapoglu B, Turkay C, Yilmaz T, Akcay A, and Kanbay M studied about the role of Helicobacter pylori in pathogenesis of upper respiratory system diseases. They found that Helicobacter pylori (H. pylori) are one of the frequently encountered micro-organisms in the aerodigestive tract. Although infections caused by $H$. pylori are this common, the exact mode of transmission has not been fully understood yet. Oral-oral, fecal-oral and gastrointestinal-oral routes are the possible modes of transmission. This infection is usually acquired in childhood and may persist for the whole life of the patient. However, about $80 \%$ of the infected humans are asymptomatic. Human stomach was considered to be the only reservoir of $H$. pylori until bacteria were discovered in human dental plaque, in oral lesions, in saliva, in tonsil and adenoid tissue. It is suggested that $H$. pylori enters the nasopharyngeal cavity by gastroesophageal reflux and colonize in the dental plaques, adenoid tissues and tonsils. From these localizations, the bacteria ascend to the middle ear and to the paranasal sinuses directly or by the reflux again and may trigger some diseases, including otitis, sinusitis, phyrangitis, laryngitis and glossitis. But still, the exact mechanism remains unclear [90]. In 2007 Mehmet Kanbay, Asiye Kanbay and Sedat Boyacioglu published a review of literature about Helicobacter pylori infection as a possible risk factor for respiratory system disease in a respiratory medicine journal. The latter said that Helicobacter pylori (HP) infection may cause extra digestive manifestations directly or indirectly, by potential mechanisms. HP infection triggers a marked local inflammatory response and a chronic systemic immune response. Some of the mediators that are thought to be possibly involved in the pathogenesis of extra digestive diseases caused by HP infection include IL-1, TNF- $\alpha$, interferon (IFN)- $\gamma$, leukotriene C4 and platelet-activating factor. Previous epidemiological and serological case control studies have revealed that HP infection might have a role in the development of chronic bronchitis, bronchiectasis, lung cancer and tuberculosis. However HP infection does not appear to have a role in the development of bronchial asthma. Considering the importance and prevalence of respiratory system diseases, it may be time to conduct well-designed sets of studies to clarify whether there is an association with HP infection and respiratory system diseases, and to answer questions that have been posed regarding the patterns of histology, genotypes of HP, and the effects of eradication therapy. The aim of this review was to analyze the possible association between HP and respiratory disease and provide a critical review of the relevant literature [91]. In 2005 Mehmet Kanbay, Gurden Gur, Sule Akcay and Ugur Yilmaz wrote an article about Helicobacter pylori seroprevalence in patients with chronic bronchitis after carrying out a study in which they found that a high rate of seropositivity for antibodies against Helicobacter pylori has been found in many extra gastrointestinal diseases. In addition, it has been reported that the risk of chronic bronchitis may be increased in subjects infected with $H$. pylori. Their study was designed to determine the $H$. pylori seroprevalence in patients with and without chronic bronchitis. 
The study enrolled 68 patients with chronic bronchitis (40 men and 28 women, aged $50.5 \pm 16.2$ years (mean standard deviation) and 95 control subjects (60 men and 35 women, aged $51.8 \pm 15.9$ years) matched for age and sex. An enzyme-linked immunosorbent assay immunoglobulin (Ig) $G$ test for $H$. pylori diagnosis was performed on all enrolled subjects (those with chronic bronchitis and controls). Fortyfive of 68 patients with chronic bronchitis (66.1\%) and 48 of 95 subjects in the control group $(57.7 \%)$ tested positive for $H$. pylori $(P=0.008)$. Rates of $H$. pylori infection are higher in patients with chronic bronchitis than in the control group. The main conclusion of this study is that $H$. pylori infection is associated with an increased prevalence chronic bronchitis. Further studies should be planned to understand the potential pathogenetic mechanisms that might underlie this association [92]. In 2003 Roussos A, Philippou N and Gourgoulianis KI wrote a review on Helicobacter pylori infection and respiratory diseases in the World J Gastroenterol Journal. They mentioned that in the past few years, a variety of extra digestive disorders, including cardiovascular, skin, rheumatic and liver diseases, have been associated with Helicobacter pylori (H. pylori) infection. The activation of inflammatory mediators by $H$. pylori seems to be the pathogenetic mechanism underlying the observed associations. Their review summarizes the current literature, including their own studies, concerning the association between $H$. pylori infection and respiratory diseases. A small number of epidemiological and serologic, case-control studies suggest that $H$. pylori infection may be associated with the development of chronic bronchitis. A frequent coexistence of pulmonary tuberculosis and $H$. pylori infection has also been found. Moreover, recent studies have shown an increased $H$. pylori seroprevalence in patients with bronchiectasis and in those with lung cancer. On the other hand, bronchial asthma seems not to be related with $H$. pylori infection. All associations between $H$. pylori infection and respiratory diseases are primarily based on case-control studies, concerning relatively small numbers of patients. Moreover, there is a lack of studies focused on the pathogenetic link between respiratory diseases and $H$. pylori infection. Therefore, they believe that larger studies should be undertaken to confirm the observed results and to clarify the underlying pathogenetic mechanisms [93]. In 1999 Caselli M, Zaffoni E, Ruina M, Sartori S, Trevisani L, Ciaccia A, Alvisi V, Fabbri L and Papi A carried out a study to evaluate the prevalence of $H$. pylori in patients with chronic bronchitis. Chronic infections such as those caused by Helicobacter pylori, Chlamydia pneumonia, and cytomegalovirus have been epidemiologically related to coronary heart disease (CHD). Other studies place $H$. pylori in relation to other extradigestive diseases. They carried out an epidemiologic pilot study to evaluate the prevalence of $H$. pylori in patients with chronic bronchitis, a respiratory disease characterized by persistent chronic inflammation, in comparison with a matched control group. An enzyme-linked immunosorbent assay IgG test for $H$. pylori diagnosis was performed in 60 consecutive patients with chronic bronchitis ( 15 women and 45 men; age range, 50-89 years; mean age, 70.38 years) and in 69 control subjects, well matched for age and social status (19 women and 50 men: age range, 52-90 years; mean age, 71.3 years). 49 of 60 patients with chronic bronchitis ( $81.6 \%$ ) and 40 of 69 subjects in the control group $(57.9 \%)$ were $H$. pylori-positive $(\mathrm{P}=0.0079)$. The odds ratio, calculated by simple analysis $(3.2)$ and confirmed by logistic regression analysis (3.399), indicated that $H$. pylori infection greatly increases the risk of chronic bronchitis. To date, $\mathrm{CHD}$ is the only convincing association between $H$. pylori infection and an extradigestive disease. The main conclusion of this pilot study is that $H$. pylori infection seems to increase the risk of developing of chronic bronchitis. An important step in this field will be to evaluate the possible change in the clinical conditions after successful eradication therapy in H. pylori-positive patients with chronic bronchitis [94].

\section{References}

1. Malfertheiner P, Megraud F, O'Morain C, Bazzoli F, El-Omar E, et al. (2007) Current concepts in the management of Helicobacter pylori infection: the Maastricht III Consensus Report. Gut 56: 772-781.

2. Vlahovic G, Russell ML, Mercer RR, Crapo JD (1999) Cellular and connective tissue changes in alveolar septal walls in emphysema. Am J Respir Crit Care Med 160: 2086-2092.

3. Qasim A, Sebastian S, Thornton O, Dobson M, McLoughlin R, et al. (2005) Rifabutin- and furazolidone-based Helicobacter pylori eradication therapies after failure of standard first- and second-line eradication attempts in dyspepsia patients. Aliment Pharmacol Ther 21: 91-96.

4. Miniño AM, Murphy SL, Xu J, Kochanek KD (2011) Deaths: final data for 2008 Natl Vital Stat Rep 59: 1-126.

5. Rennard SI, Vestbo J (2006) COPD: the dangerous underestimate of $15 \%$ Lancet 367: 1216-1219.

6. Global strategy for the diagnosis, and prevention of chronic obstructive pulmonary disease, Global Initiative for Chronic Obstructive Lung Disease (GOLD).

7. Rabe KF, Hurd S, Anzueto A, Barnes PJ, Buist SA, et al. (2007) Global strategy for the diagnosis, management, and prevention of chronic obstructive pulmonary disease: GOLD executive summary. Am J RespirCrit Care Med 176 532-555.

8. Celli BR, MacNee W; ATS/ERS Task Force (2004) Standards for the diagnosis and treatment of patients with COPD: a summary of the ATS/ERS position paper. EurRespir J 23: 932-946.

9. PIERCE JA, HOCOTT JB, EBERT RV (1961) The collagen and elastin content of the lung in emphysema. Ann Intern Med 55: 210-222.

10. Rennard SI (1998) COPD: overview of definitions, epidemiology, and factors influencing its development. Chest 113: 235S-241S.

11. Centers for Disease Control and Prevention (CDC) (2012) Chronic obstructive pulmonary disease among adults--United States, 2011. MMWR Morb Mortal Wkly Rep 61: 938-943

12. Buist AS, McBurnie MA, Vollmer WM, Gillespie S, Burney P, et al. (2007) International variation in the prevalence of COPD (the BOLD Study): population-based prevalence study. Lancet 370: 741-750.

13. Gershon AS, Warner L, Cascagnette P, Victor JC, To T (2011) Lifetime risk of developing chronic obstructive pulmonary disease: a longitudinal population study. Lancet Infect Dis 378: 991-996.

14. McDonough JE, Yuan R, Suzuki M, Seyednejad N, Elliott WM, et al. (2011) Small-airway obstruction and emphysema in chronic obstructive pulmonary disease. N Engl J Med 365: 1567-1575.

15. G I f A G (2012) Global Strategy for Asthma Management and Prevention.

16. Siafakas NM, Vermeire P, Pride NB, Paoletti P, Gibson J, et al. (1995) Optimal assessment and management of chronic obstructive pulmonary disease (COPD). The European Respiratory Society Task Force. EurRespir J 8: 13981420.

17. Rosenbloom J, Campbell EJ, Mumford R, Saldeen T, Senior RM, et al. (1991) Biochemical/immunologic markers of emphysema. Ann N Y AcadSci 624: 7-12.

18. O'Brien C, Guest PJ, Hill SL, Stockley RA (2000) Physiological and radiological characterisation of patients diagnosed with chronic obstructive pulmonary disease in primary care. Thorax 55: 635-642.

19. Jeffery PK (2000) Comparison of the structural and inflammatory features of COPD and asthma. Giles F. Filley Lecture. Chest 117: 251S-60S.

20. Aoshiba K, Nagai A (2004) Differences in airway remodeling between asthma and chronic obstructive pulmonary disease. Clin Rev Allergy Immunol 27: 3543.

21. Hogg JC, Chu F, Utokaparch S, Woods R, Elliott WM, et al. (2004) The nature of small-airway obstruction in chronic obstructive pulmonary disease. $\mathrm{N}$ Engl J Med 350: 2645-2653

22. Kuempel ED, Wheeler MW, Smith RJ, Vallyathan V, Green FH (2009) Contributions of dust exposure and cigarette smoking to emphysema severity in coal miners in the United States. Am J RespirCrit Care Med 180: 257-264.

23. Qaseem A, Wilt TJ, Weinberger SE, Hanania NA, Criner G, et al. (2011) 
Diagnosis and management of stable chronic obstructive pulmonary disease: a clinical practice guideline update from the American College of Physicians, American College of Chest Physicians, American Thoracic Society, and European Respiratory Society. Ann Intern Med 155: 179-191.

24. Lamprecht B, McBurnie MA, Vollmer WM, Gudmundsson G, Welte T, et al. (2011) COPD in never smokers: results from the population-based burden of obstructive lung disease study. Chest 139: 752-763.

25. Kessler R, Partridge MR, Miravitlles M, Cazzola M, Vogelmeier C, et al. (2011) Symptom variability in patients with severe COPD: a pan-European crosssectional study. EurRespir J 37: 264-272.

26. Sin DD, Wu L, Man SF (2005) The relationship between reduced lung function and cardiovascular mortality: a population-based study and a systematic review of the literature. Chest 127: 1952-1959.

27. Badgett RG, Tanaka DJ, Hunt DK, Jelley MJ, Feinberg LE, et al. (1993) Can moderate chronic obstructive pulmonary disease be diagnosed by historical and physical findings alone? Am J Med 94: 188-196.

28. Garcia-Pachon E, Padilla-Navas I (2006) Frequency of Hoover's sign in stable patients with chronic obstructive pulmonary disease. Int J ClinPract 60: 514517.

29. American Thoracic Society; European Respiratory Society (2003) American Thoracic Society/European Respiratory Society statement: standards for the diagnosis and management of individuals with alpha-1 antitrypsin deficiency. Am J RespirCrit Care Med 168: 818-900.

30. Shirtcliffe P, Weatherall M, Marsh S, Travers J, Hansell A, et al. (2007) COPD prevalence in a random population survey: a matter of definition. EurRespir $\mathrm{J}$ 30: $232-239$

31. Mannino DM, Diaz-Guzman E (2012) Interpreting lung function data using $80 \%$ predicted and fixed thresholds identifies patients at increased risk of mortality. Chest 141: 73-80.

32. Miller MR, Hankinson J, Brusasco V, Burgos F, Casaburi R, et al. (2005) Standardisation of spirometry. EurRespir J 26: 319-338.

33. Baraldo S, Turato G, Badin C, Bazzan E, Beghé B, et al. (2004) Neutrophilic infiltration within the airway smooth muscle in patients with COPD. Thorax 59: 308-312.

34. Kelly AM, McAlpine R, Kyle E (2001) How accurate are pulse oximeters in patients with acute exacerbations of chronic obstructive airways disease? Respir Med 95: 336-340.

35. Matthay RA, Niederman MS, Wiedemann HP (1990) Cardiovascular-pulmonary interaction in chronic obstructive pulmonary disease with special reference to the pathogenesis and management of corpulmonale. Med Clin North Am 74 $571-618$.

36. Klein JS, Gamsu G, Webb WR, Golden JA, Müller NL (1992) High-resolution CT diagnosis of emphysema in symptomatic patients with normal chest radiographs and isolated low diffusing capacity. Radiology 182: 817-821.

37. Hasegawa M, Nasuhara Y, Onodera Y, Makita H, Nagai K, et al. (2006) Airflow limitation and airway dimensions in chronic obstructive pulmonary disease. Am J RespirCrit Care Med 173: 1309-1315.

38. Qaseem A, Snow V, Shekelle P, Sherif K, Wilt TJ, et al. (2007) Clinical Efficacy Assessment Subcommittee of the American College of Physicians, Diagnosis and management of stable chronic obstructive pulmonary disease: a clinical practice guideline from the American College of Physicians. Ann Intern Med 147: 633-638.

39. U.S. Preventive Services Task Force (2008) Screening for chronic obstructive pulmonary disease using spirometry: U.S. Preventive Services Task Force recommendation statement. Ann Intern Med 148: 529-534.

40. de Marco R, Accordini S, Antò JM, Gislason T, Heinrich J, et al. (2009) Longterm outcomes in mild/moderate chronic obstructive pulmonary disease in the European community respiratory health survey. Am J RespirCrit Care Med 180: 956-963.

41. Jones PW, Tabberer M, Chen WH (2011) Creating scenarios of the impact of COPD and their relationship to COPD Assessment Test (CATâ, $\notin)$ scores. BMC Pulm Med 11: 42

42. Wilson CB, Jones PW, O'Leary CJ, Cole PJ, Wilson R (1997) Validation of the St. George's Respiratory Questionnaire in bronchiectasis. Am J RespirCrit Care Med 156: 536-541.

43. Celli BR, Cote CG, Marin JM, Casanova C, Montes de Oca M, et al. (2004) The body-mass index, airflow obstruction, dyspnea, and exercise capacity index in chronic obstructive pulmonary disease. N Engl J Med 350: 1005-1012.

44. Jones RC, Donaldson GC, Chavannes NH, Kida K, Dickson-Spillmann M, et al. (2009) Derivation and validation of a composite index of severity in chronic obstructive pulmonary disease: the DOSE Index. Am J RespirCrit Care Med 180: 1189-1195.

45. Puhan MA, Garcia-Aymerich J, Frey M, terRiet G, Antó JM, et al. (2009) Expansion of the prognostic assessment of patients with chronic obstructive pulmonary disease: the updated BODE index and the ADO index. Lancet 374 704-711.

46. Gisbert JP, Gonzalez L, Calvet X (2005) Systematic review and meta-analysis: proton pump inhibitor vs. ranitidine bismuth citrate plus two antibiotics in Helicobacter pylori eradication. Helicobacter 10: 157-171.

47. Marshall BJ, Rogers PA, Glancy RJ (1987) History of the discovery of C. pylori. Campylobacter Pylori in Gastritis and Peptic Ulcer Disease.

48. Marshall BJ, Warren JR (1984) Unidentified curved bacilli in the stomach of patients with gastritis and peptic ulceration. Lancet 1: 1311-1315.

49. Goodwin CS (1993) Microbiology of Helicobacter pylori. GastroenterolClin North Am 22: 5

50. [No authors listed] (1994) NIH Consensus Conference. Helicobacter pylor in peptic ulcer disease. NIH Consensus Development Panel on Helicobacter pylori in Peptic Ulcer Disease. JAMA 272: 65-69.

51. Practice Parameters Committee of the American College of Gastroenterology, Chey WD, Wong BC (2007) American College of Gastroenterology guideline on the management of Helicobacter pylori infection. Am J Gastroenterol 102 1808-1825.

52. Malfertheiner P, Megraud F, O'Morain CA, Atherton J, Axon AT, et al. (2012) Management of Helicobacter pylori infection--the Maastricht IV/ Florence Consensus Report. Gut 61: 646-664.

53. [No authors listed] (1995) Standards for the diagnosis and care of patients with chronic obstructive pulmonary disease. American Thoracic Society. Am J Respir Crit Care Med 152: S77-121.

54. Petty TL, Silvers GW, Stanford RE (1987) Mild emphysema is associated with reduced elastic recoil and increased lung size but not with air-flow limitation. Am Rev Respir Dis 136: 867-871.

55. Graham DY, Shiotani A (2012) Which Therapy for Helicobacter pylori Infection? Gastroenterology 143: 10-12.

56. Khattab NF, EL-Nashar NA, Nessrien M El-Margoshy, Henna LN (2010) Seroprevalence of Helicobacter Pylori in Patients with Chronic Obstructive Pulmonary Disease and its Relation to Pulmonary Function Tests 78: 1.

57. Mitz HS, Farber SS (1993) Demonstration of Helicobacter pylori in tracheal secretions. Am Osteopath Assoc 93: 87-91.

58. Fuccio L, Minardi ME, Zagari RM, Grilli D, Magrini N, et al. (2007) Metaanalysis: duration of first-line proton-pump inhibitor based triple therapy for Helicobacter pylori eradication. Ann Intern Med 147: 553-562.

59. Hashemi SH, Nadi E, Hajilooi M, Seif-Rabiei MA, Roustaei U (2011) Relationship between Helicobacter pylori Infection and Chronic Obstructive Pulmonary Disease. ActaMedicalranica 49: 721-724.

60. Tsang KW, Lam SK, Lam WK, Karlberg J, Wong BC, et al. (1998) High seroprevalence of Helicobacter pylori in active bronchiectasis. Am J RespirCrit Care Med 158: 1047-1051.

61. Tepes B, O'Connor A, Gisbert JP, O'Morain C (2012) Treatment of Helicobacter pylori infection 2012. Helicobacter 17: 36-42.

62. Horvath A, Dziechciarz P, Szajewska H (2012) Meta-analysis: sequential therapy for Helicobacter pylori eradication in children. Aliment PharmacolTher 36: $534-541$.

63. Fischbach LA, Goodman KJ, Feldman M, Aragaki C (2002) Sources of variation of Helicobacter pylori treatment success in adults worldwide: a meta-analysis. Int J Epidemiol 31: 128-139.

64. Dixon MF, Genta RM, Yardley JH, Correa P (1996) Classification and grading of gastritis. The updated Sydney System. International Workshop on the Histopathology of Gastritis, Houston 1994. Am J SurgPathol 20: 1161-1181.

65. Carpenter HA, Talley NJ (1995) Gastroscopy is incomplete without biopsy: clinical relevance of distinguishing gastropathy from gastritis. Gastroenterolog 108: 917-924. 
Citation: Deerpaul D, Hui SY (2014) The Study of Association between Helicobacter pylori (H. pylori) and Chronic Obstructive Pulmonary Disease (COPD). J Pulm Respir Med 4: 171. doi:10.4172/2161-105X. 1000171

Page 14 of 14

66. Yardley JH (1995) Gastritis, duodenitis, and associated ulcerative lesions. Textbook of Gastroenterology.

67. Yardley JH (1999) Gastritis, duodenitis, and associated ulcerative lesions. Textbook of Gastroenterology, (3rdedn)

68. Ciociola AA, McSorley DJ, Turner K, Sykes D, Palmer JB (1999) Helicobacter pylori infection rates in duodenal ulcer patients in the United States may be lower than previously estimated. Am J Gastroenterol 94: 1834-1840.

69. Tytgat G, Rauws E, Rietra P (1985) Campylobacter-like organism (CLO) in the human stomach. Gastroenterology 88: 1620.

70. McColl KE, el-Nujumi AM, Chittajallu RS, Dahill SW, Dorrian CA, et al. (1993) A study of the pathogenesis of Helicobacter pylori negative chronic duodenal ulceration. Gut 34: 762-768.

71. Bytzer P, Teglbjaerg PS; Danish Ulcer Study Group (2001) Helicobacter pylorinegative duodenal ulcers: prevalence, clinical characteristics, and prognosisresults from a randomized trial with 2-year follow-up. Am J Gastroenterol 96 1409-1416.

72. Harris AW, Gummett PA, Phull PS, Jacyna MR, Misiewicz JJ, et al. (1997) Recurrence of duodenal ulcer after Helicobacter pylori eradication is related to high acid output. Aliment PharmacolTher 11: 331-334.

73. Marshall BJ, McGechie DB, Rogers PA, Glancy RJ (1985) Pyloric Campylobacter infection and gastroduodenal disease. Med J Aust 142: 439-444.

74. Borody TJ, George LL, Brandl S, Andrews P, Ostapowicz N, et al. (1991) Helicobacter pylori-negative duodenal ulcer. Am J Gastroenterol 86: 1154-1157.

75. Dwyer B, Sun NX, Kaldor J, Tee W, Lambert J, et al. (1988) Antibody response to Campylobacter pylori in an ethnic group lacking peptic ulceration. Scand $J$ Infect Dis 20: 63-68.

76. Gatta L, Zullo A, Perna F, Ricci C, De Francesco V, et al. (2005) A 10-day levofloxacin-based triple therapy in patients who have failed two eradication courses. Aliment PharmacolTher 22: 45-49.

77. Fischbach LA, van Zanten S, Dickason J (2004) Meta-analysis: the efficacy, adverse events, and adherence related to first-line anti-Helicobacter pylori quadruple therapies. Aliment PharmacolTher 20: 1071-1082.

78. Graham DY, Hammoud F, El-Zimaity HM, Kim JG, Osato MS, et al. (2003) Meta-analysis: proton pump inhibitor or $\mathrm{H} 2$-receptor antagonist for Helicobacter pylori eradication. Aliment PharmacolTher 17: 1229-1236.

79. Vakil N, Connor J (2005) Helicobacter pylori eradication: equivalence trials and the optimal duration of therapy. Am J Gastroenterol 100: 1702-1703.

80. Yemisen M, Mete B, Kanbay A, Balkan II, Ozaras R (2012) The Role of
Helicobacter pylori in Upper Respiratory System Infections: Is it More Than Colonization? Curr Infect Dis Rep 14: 128-136.

81. D'Elios MM, de Bernard M (2010) To treat or not to treat Helicobacter pylori to benefit asthma patients. Expert Rev Respir Med 4: 147-150.

82. Vakil N (2009) Helicobacter pylori. Can Helicobacter pylori infection prevent allergic asthma? Rev GastroenterolDisord 9: E66-67.

83. Sachs G, Scott DR (2012) Helicobacter pylori: Eradication or Preservation F1000 Med Rep 4: 7

84. Snaith A, El-Omar EM (2008) Helicobacter pylori: host genetics and disease outcomes. Expert Rev GastroenterolHepatol 2: 577-585.

85. Wang Y, Bi Y, Zhang L, Wang C (2012) Is Helicobacter pylori infection associated with asthma risk? A meta-analysis based on 770 cases and 785 controls. Int J Med Sci 9: 603-610

86. Hasni SA (2012) Role of Helicobacter pylori infection in autoimmune diseases CurrOpinRheumatol 24: 429-434.

87. MinovJ, Karadzinska-Bislimovska J, Vasilevska K, Risteska-Kuc S, Saso S et al. (2012)Helicobacter Pylori Infection in Never-Smoking Male Patients with Chronic Obstructive Pulmonary Disease and its Relation to Lung Function. American Journal of Immunology 8: 146.

88. Malfertheiner MV, Kandulski A, Schreiber J, Malfertheiner P (2011) Helicobacte pylori infection and the respiratory system: a systematic review of the literature. Digestion 84: 212-220.

89. Azza MA, Ayat A M, Sally AF, Nagwa AK, Somaya M, et al. (2011) Helicobacter Pylori Infection in Egyptian Children with Bronchial Asthma. International Journal of Academic Research 3: 484

90. Kurtaran H, Uyar ME, Kasapoglu B, Turkay C, Yilmaz T, et al. (2008) Role of Helicobacter pylori in pathogenesis of upper respiratory system diseases. $J$ Natl Med Assoc 100: 1224-1230.

91. Kanbay M, Kanbay A, Boyacioglu S (2007) Helicobacter pylori infection as a possible risk factor for respiratory system disease: a review of the literature. Respir Med 101: 203-209.

92. KanbayemailM, GurG, Akcay S, Ugur Y (2005) Helicobacter pylor seroprevalence in patients with chronic bronchitis. Respiratory Medicine 99: 1213-1216.

93. Roussos A, Philippou N, Gourgoulianis KI (2003) Helicobacter pylori infection and respiratory diseases: a review. World J Gastroenterol 9: 5-8.

94. Caselli M, Zaffoni E, Ruina M, Sartori S, Trevisani L, et al. (1999) Helicobacter pylori and chronic bronchitis. Scand J Gastroenterol 34: 828-830. 